\title{
Computational modeling of temporal and sequential dynamics of foraging decisions
}

\author{
Kanghoon Jung ${ }^{1,2}$, Hyeran Jang ${ }^{1}$, Jerald D Kralik², Jaeseung Jeong ${ }^{1 *}$ \\ From The Twenty Third Annual Computational Neuroscience Meeting: CNS*2014 \\ Québec City, Canada. 26-31 July 2014
}

\section{Background}

A fundamental understanding of behavior requires predicting when and what an individual will choose. However, the actual temporal and sequential dynamics of successive choices made among multiple alternatives remain unclear.

\section{Methods}

In the current study, we tested the hypothesis that there is a general bursting property in both the timing and sequential patterns of foraging decisions. We conducted a foraging experiment in which rats chose among four different foods over a continuous two-week time period.

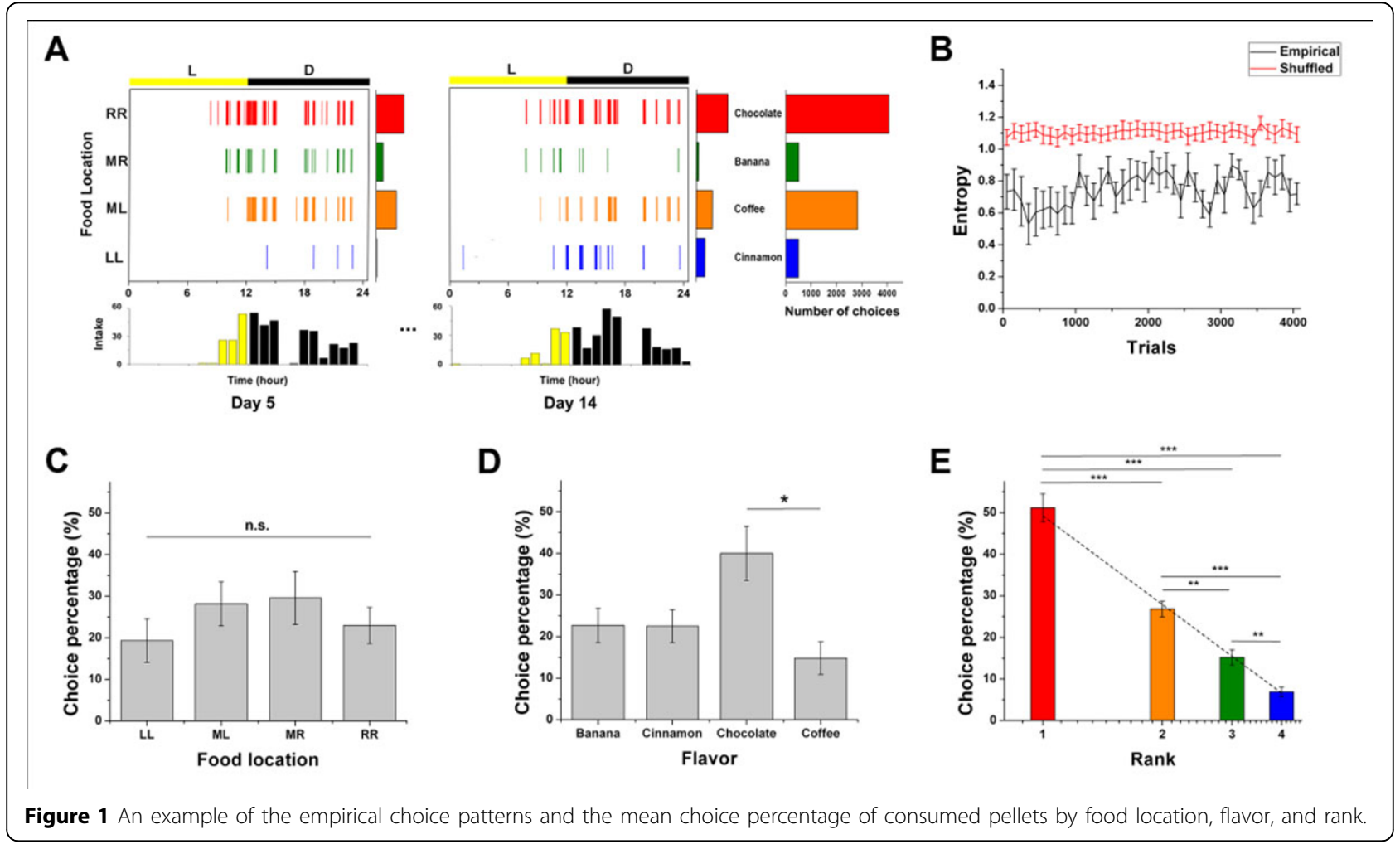

'Department of Bio and Brain Engineering, Korea Advanced Institute of

Science and Technology (KAIST), Daejeon 305-701, Korea

Full list of author information is available at the end of the article

(c) 2014 Jung et al; licensee BioMed Central Ltd. This is an Open Access article distributed under the terms of the Creative Commons 

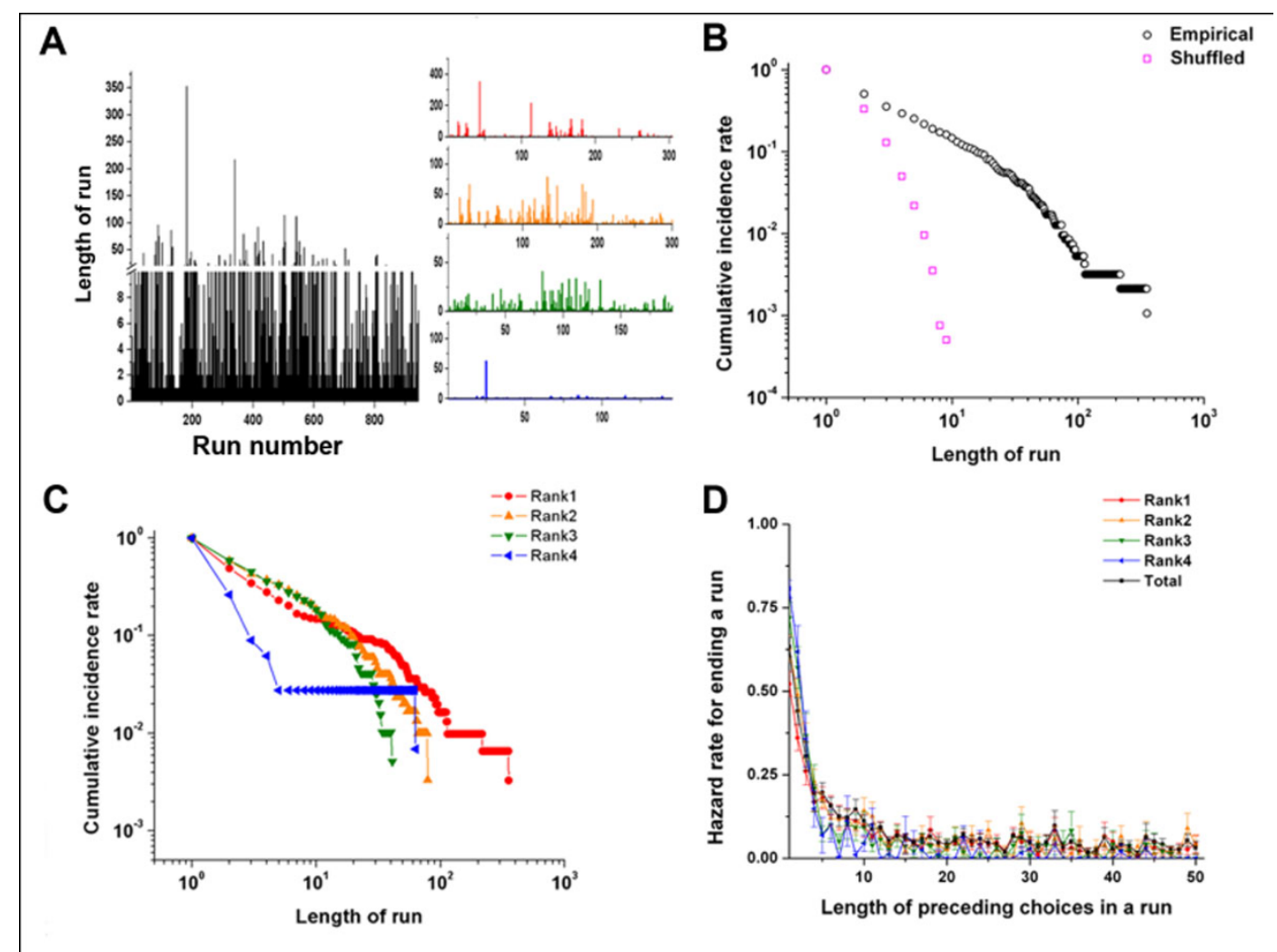

Figure 2 Temporal features of the foraging behavior.
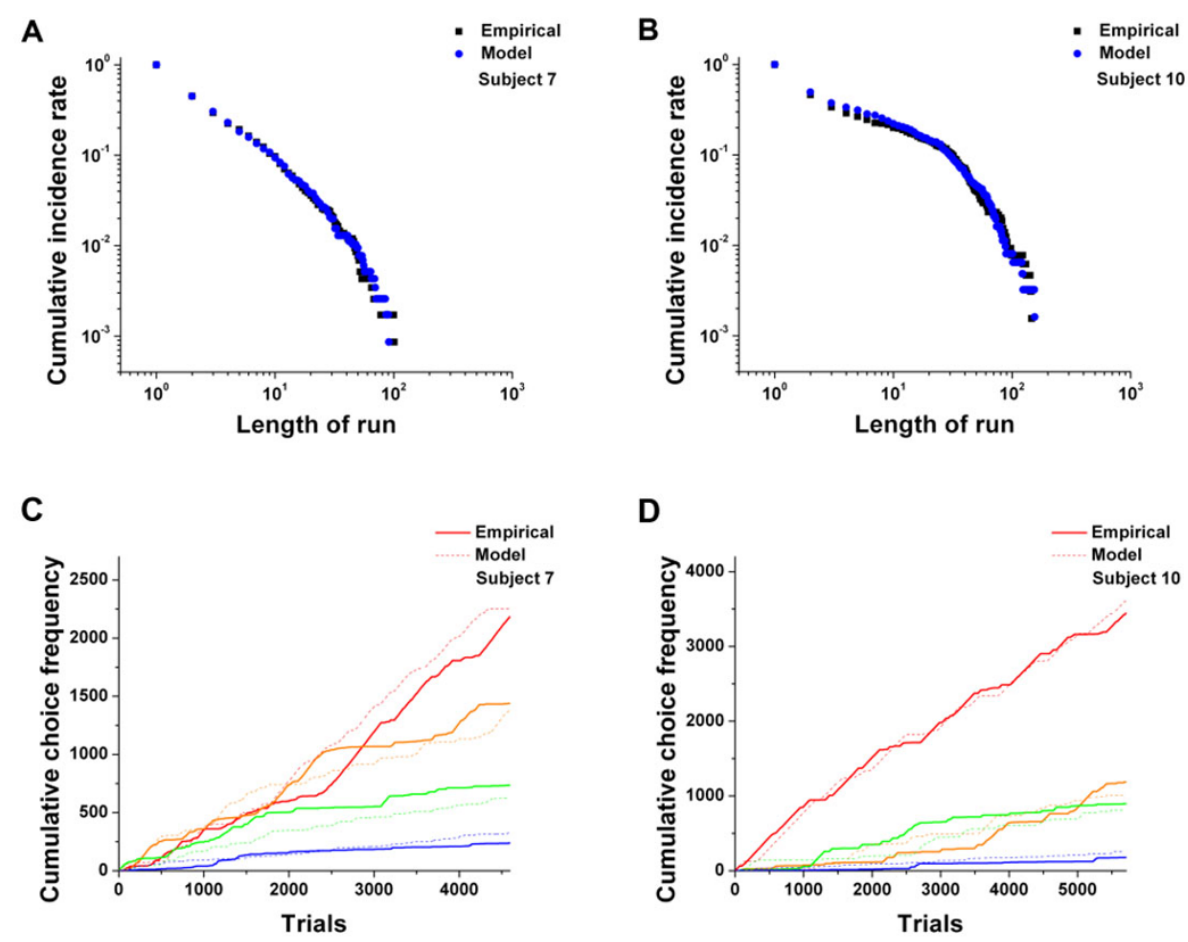

Figure 3 Comparison of a choice sequence generated from the dual-control model with the empirical data from two representative rats. 
Regarding when choices were made, we found bursts of rapidly occurring actions separated by time-varying inactive periods, partially based on a circadian rhythm.

\section{Results}

Regarding what was chosen, we found sequential dynamics in affective choices characterized by two key features: (a) a highly biased choice distribution; and (b) preferential attachment, in which the animals were more likely to choose what they had previously chosen. To capture the temporal dynamics, we propose a dual-state model consisting of active and inactive states. We also introduce a satiation-attainment process for bursty activity, and a non-homogeneous Poisson process for longer inactivity between bursts. For the sequential dynamics, we propose a dual-control model consisting of goal-directed and habit systems, based on outcome valuation and choice history, respectively.

\section{Conclusions}

This study provides insights into how the bursty nature of behavior emerges from the interaction of different underlying systems, leading to heavy tails in the distribution of behavior over time and choices.

\section{Authors' details}

${ }^{1}$ Department of Bio and Brain Engineering, Korea Advanced Institute of Science and Technology (KAIST), Daejeon 305-701, Korea. ${ }^{2}$ Department of Psychological and Brain Sciences, Dartmouth College, Hanover, NH 03755, USA.

Published: 21 July 2014

\section{References}

1. Barabási A-L: The origin of bursts and heavy tails in human dynamics. Nature 2005, 435:207-211.

2. Kable JW, Glimcher PW: The neurobiology of decision: consensus and controversy. Neuron 2009, 63:733-745.

3. Dayan P, Balleine BW: Reward, motivation, and reinforcement learning Neuron 2002, 36:285-298.

doi:10.1186/1471-2202-15-S1-P137

Cite this article as: Jung et al:: Computational modeling of temporal and sequential dynamics of foraging decisions. BMC Neuroscience 2014 15(Suppl 1):P137.

\section{Submit your next manuscript to BioMed Central} and take full advantage of:

- Convenient online submission

- Thorough peer review

- No space constraints or color figure charges

- Immediate publication on acceptance

- Inclusion in PubMed, CAS, Scopus and Google Scholar

- Research which is freely available for redistribution

Submit your manuscript at www.biomedcentral.com/submit 